\title{
Investigation of the effects of the equivalent circuit parameters on induction motor torque using three different equivalent circuit models
}

\author{
Mehmet Murat Tezcan ${ }^{1}$, Asim Gökhan Yetgin ${ }^{1, *}$, Ali Ihsan Canakoglu ${ }^{1}$, Barlş Cevher ${ }^{2}$, \\ Mustafa Turan ${ }^{2}$, Murat Ayaz ${ }^{3}$ \\ ${ }^{1}$ Dumlupınar University, Electrical and Electronics Engineering, Kutahya, 43100, Turkey \\ ${ }^{2}$ Sakarya University, Electrical and Electronics Engineering, Sakarya, 54000, Turkey \\ ${ }^{3}$ Kocaeli University, Technical Education Faculty, Kocaeli, 41000, Turkey
}

\begin{abstract}
In this study, the most vital characteristic properties of induction motor, motor starting, maximum and nominal torque are analyzed for what are affected. For the analysis of torque, L type, T type and IEEE 112 equivalent circuit model is employed. Torque change is investigated with the help of codes developed in MATLAB to be used in electrical machines course. First, the slip-moment characteristic curve of the induction motor is divided into three working zones and it was determined which equivalent circuit model gave the best results in these study zones. Later, such parameters as stator and rotor resistance, stator and rotor reactance, magnetization reactance, core resistance and slip are researched for how torque values are affected from. The obtained values for each of the three equivalent circuit models are given and compared with experimental results. $50 \mathrm{HP}$ squirrel cage induction motor parameters are used in analysis. In the analysis, the most influential parameters on the starting torque are found as rotor resistance and stator and rotor reactance. Change of other parameters' impact ratio depending upon right proportion and inverse proportion is observed. When nominal torque variations are investigated, again rotor resistance is the most influential parameter and by selecting proper factor effecting rotor resistance during design, the result of acquiring desired rotor resistance is obtained. When the maximum torque variations are examined, it appears that the stator and rotor reactance values are effective. Starting, maximum and nominal torque expressions change with square of voltage alters the effect on them a lot. Therefore, triangle or star connection importance arises during machine design.
\end{abstract}

Keywords: Induction motor, Nominal torque, Starting torque, Maximum torque, Equivalent circuit models, Motor parameters.

\section{Introduction}

Induction machines is widely used in many applications in terms of specifications such as simple and robust structure, low cost, wide speed adjustment, low maintenance requirement, wide power range, reliable operation, mass production technology and etc. In

* Corresponding author: gokhan.yetgin@dpu.edu.tr

Reviewers: Maciej Bodnicki, Josef Soukup 
addition, induction machines are easier and cheaper to produce compared with other electric machines because they do not contain permanent magnets, brushes, or collectors [16]. Especially, induction motors are the preferred motors in industrial applications as they can be operated directly on line voltage and their speeds remain constant under load.

In addition, speed and position controls of induction machines can be made easily and this specification makes them advantageous over other industrial machines [5]. However, the low efficiency compared to the permanent magnet synchronous motors and the need high current values for starting operation are the major disadvantages of induction machines. In order to eliminate this drawback, designer should make a preliminary modeling and determine the physical size via parametric optimization with modern software in accordance with the requirements of the application [4]. Machine designers improve performance of electric machines with optimization some parameters such as winding structure, geometry of rotor slots, size of the short circuit ring, geometry of rotor bars, number of stator slots, number of rotor bars, amount and type of magnetic steel and etc. Most of standard T-frame induction motors with squirrel cage are attempted to be designed to have "design B features" of the National Electrical Manufacturers Association (NEMA). Some applications may require torque-speed characteristics outside the "design B feature", and a higher starting torque may require (e.g., for a loaded conveyor) than the capacity of "design B feature". In this case, a machine produced having "design C features" of the NEMA can be selected or machine having higher output power with "design B features" must be selected [7]. Moment-speed characteristics of NEMA standards are collected in 4 different machine groups [8].

Harson et al. and Song et al. have investigated the effects of some design parameters such as air gap length, slot opening, skewed rotor bars, and slot combination on torquespeed characteristics of induction machines [1]. Kul has shown in his study that by choosing a large number of rotor slots, starting torque of the induction machines can be increased [9]. Usudum has stated in his study that the change of the air gap value causes two kinds of effects both as advantages and disadvantages in terms of machine efficiency and performance. As the air gap value decreases, the magnetic saturations in the teeth increase; so that torque ripples and harmonics of the phase current occur and the iron losses increase. On the other hand, as the air gap value decreases, both the starting current value and the nominal operation current value decrease and the copper losses decrease due to decreasing of the current value [10].

In this study, torque expressions of an induction machine with three-phase squirrel cage have been analyzed for using in electrical machinery lessons using three different equivalent circuit models. The slip-torque diagram of the induction machine has been divided into three parts, and it is determined which equivalent circuit model converges better to the experimental results in these parts. Then, it has been investigated how the starting, nominal and maximum torque values vary with changing the equivalent circuit parameters of the induction machine using three different circuit models. For this purpose, the parameters such as slip, stator and rotor resistances, stator and rotor leakage reactance, magnetization reactance and iron resistance have been changed at certain intervals and the change of torque values has been investigated.

\section{Torque of induction motors}

The torque, also referred to as the turning moment, is a force applied to rotate an object around an axis. In an electric machine, the torque is expressed as the ratio of the motor power to the angular velocity. It is clear that the torque value can be calculated with this basic expression, by using some known parameters of the machine. However, it is important to note that the moment-speed curve of each induction motor is unique. As can 
be seen from the expression of torque, when the speed is increased, a decrease in torque value will be seen. However, it should be taken consideration that the speed at which the maximum torque produced by the three-phase induction motor with a squirrel cage is generated and the speed at which the maximum power is generated are different from each other [11].

The torque-speed characteristic of induction motors is usually determined using equivalent circuit parameters. These parameters are derived from measurements of the open circuit and short circuit tests [12]. In induction motors, the torque values calculated by using equivalent circuit models and of L type, T type and IEEE type are given in Table 1. As can be seen, moment expression varies depending on many parameters. $L$ type, $T$ type and IEEE type equivalent circuit models of induction motor are shown in Fig. 1 [13-15].
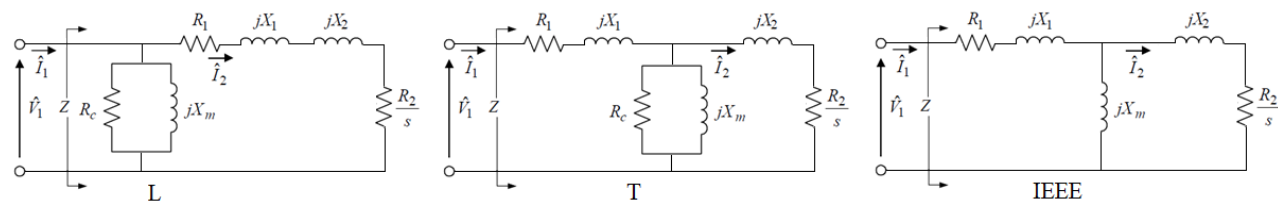

Fig. 1. L, T and IEEE equivalent circuit models of induction motor

In Fig. $1, V_{1}$ is grid voltage, $I_{1}$ is the stator current, $I_{2}$ is rotor current, $R_{1}$ and $R_{2}$ are respectively stator winding resistance and rotor resistance with referred to stator winding, $R_{c}$ is iron resistance, $X_{m}$ is magnetization reactance, $X_{1}$ and $X_{2}$ are respectively the stator reactance and rotor reactance with referred to stator, $Z$ is equivalent impedance and $s$ refers slip value. As seen from Fig. 1, the equivalent impedance values obtained from all three models are different from each other. The variation of impedance value causes to change of current value drawn from the grid. Thus, the output power and shaft torque values to be obtained vary.

The moment calculations are given in Table 1 using $\mathrm{L}$ type, $\mathrm{T}$ type and IEEE type equivalent circuit models and parameters of induction motors. As can be seen, moment expressions vary depending on many parameters.

Table 1. Torque formulations of $\mathrm{L}, \mathrm{T}$ and IEEE equivalent circuit models $[6,12,13,16-18]$

\begin{tabular}{|c|c|c|c|}
\hline & $\mathrm{L}$ & $\mathrm{T}$ & IEEE \\
\hline \multirow[t]{2}{*}{ Torque } & $\begin{array}{r}T=\frac{m \cdot p \cdot R_{2}}{2 \cdot \pi \cdot f \cdot s} \cdot \\
V_{1}^{2}\end{array}$ & $\begin{aligned} T=\frac{m \cdot p \cdot R_{2}}{2 \cdot \pi \cdot f \cdot s} & \\
& V_{t h}^{2}\end{aligned}$ & $\begin{aligned} T=\frac{m \cdot p \cdot R_{2}}{2 \cdot \pi \cdot f \cdot s} & \\
& V_{t h}^{2}\end{aligned}$ \\
\hline & {$\left[\left(R_{1}+\frac{R_{2}}{s}\right)^{2}+\left(X_{1}+X_{2}\right)^{2}\right]$} & {$\left[\left(R_{t h}+\frac{R_{2}}{s}\right)^{2}+\left(X_{t h}+X_{2}\right)^{2}\right]$} & $\overline{\left[\left(R_{t h}+\frac{R_{2}}{s}\right)^{2}+\left(X_{t h}+X_{2}\right)^{2}\right]}$ \\
\hline Voltage & $V_{l}$ & $V_{t h}=\frac{R_{\mathcal{C}} X_{m}}{R_{1}+j X_{1}+R_{C} X_{m}} \cdot V_{1}$ & $V_{t h}=\frac{j X_{m}}{R_{1}+j X_{1}+j X_{m}} \cdot V_{1}$ \\
\hline Impedance & $Z_{t h}=R_{1}+R 2+j X_{1}+j X_{2}$ & $Z_{t h}=\frac{R_{C} X_{m} \cdot\left(R_{1}+j X_{1}\right)}{R_{C} X_{m}+R_{1}+j X_{1}}$ & $Z_{t h}=\frac{j X_{m} \cdot\left(R_{1}+j X_{1}\right)}{j X_{m}+R_{1}+j X_{1}}$ \\
\hline $\begin{array}{l}\text { Maximum } \\
\text { slip }\end{array}$ & $s_{\max }= \pm \frac{R_{2}}{\sqrt{R_{1}^{2}+\left(X_{1}+X_{2}\right)^{2}}}$ & $s_{\max }= \pm \frac{R_{2}}{\sqrt{R_{t h}^{2}+\left(X_{t h}+X_{2}\right)^{2}}}$ & $s_{\max }= \pm \frac{R_{2}}{\sqrt{R_{t h}^{2}+\left(X_{t h}+X_{2}\right)^{2}}}$ \\
\hline
\end{tabular}

In Table $1, p$ is the number of poles, $f$ is the frequency, $R_{t h}$ is the thevenin equivalent resistance, $X_{t h}$ is the thevenin reactance, $V_{t h}$ is the thevenin voltage, $s_{\max }$ is the maximum slip, $T$ is the torque, $m$ refers the number of phases. In order to find the nominal torque, the 
starting torque and the maximum torque in the calculations, the results is obtained by writing $s=s_{n}, s=1$ and $s=s_{\max }$ in place of the slip value in the torque expression in all three models.

As shown in Table 1, the torque expressions of equivalent circuit models of $T$ type and IEEE type are identical to each other. Calculations of the torque value are made using thevenin method in both models. However, since the iron resistance is neglected in the IEEE model, the difference in torque expressions arises due to the change in the thevenin equivalent impedance and the thevenin voltage.

The slip-torque characteristic curve of the induction motor can be analyzed with divided into 3 operation regions. These operation regions are shown in Fig. 2 [19].

- The first operation region is the low slip (high speed) region.

- The second operation region is the unsteady region. The maximum torque is obtained in this region.

- The third operation region is the high slip (low speed) region.

The manufacturer's information and experimental data for the three-phase squirrel cage induction motor used in the calculations are given in Table 2.

Table 2. Manufacture and experimental data of the induction motor [20]

\begin{tabular}{|l|c|}
\hline \multicolumn{1}{|c|}{ Parameters } & Values \\
\hline Stator resistance (ohm) & 0.087 \\
\hline Rotor resistance (ohm) & 0.228 \\
\hline Stator leakage reactance (ohm) & 0.489 \\
\hline Rotor leakage reactance (ohm) & 0.115 \\
\hline Core resistance (ohm) & 23 \\
\hline Magnetization reactance (ohm) & 13.08 \\
\hline Number of pole (2p) & 4 \\
\hline Number of phase & 3 \\
\hline Frequency $(\mathrm{Hz})$ & 60 \\
\hline Voltage (V) & 460 \\
\hline Power $(\mathrm{HP})$ & 50 \\
\hline Winding connection & Star \\
\hline Rotor speed (rpm) & 1705 \\
\hline Stator speed (rpm) & 1800 \\
\hline Nominal Torque $(\mathrm{N} \cdot \mathrm{m})$ & 234 \\
\hline Starting Torque $(\mathrm{N} \cdot \mathrm{m})$ & 529 \\
\hline Maximum Torque $(\mathrm{N} \cdot \mathrm{m})$ & 773 \\
\hline
\end{tabular}

\section{Obtained Results}

\subsection{Effect of slip}

Most important performance parameter for induction motor is slip. Slip value for an induction motor is calculated with $s=\frac{n_{S}-n_{r}}{n_{S}} \cdot 100$. As known, $n_{r}$ is the shaft speed, $n_{s}$ is the synchronous speed or rotating magnetic field speed. For starting conditions, rotor speed is near zero and the slip value is near to 1 . With the increasing of the shaft speed, slip value decreases and gets close to zero [19]. Fig. 2 shows the slip-output torque curves of the induction machine with the obtained results from three equivalent steady-state model. 


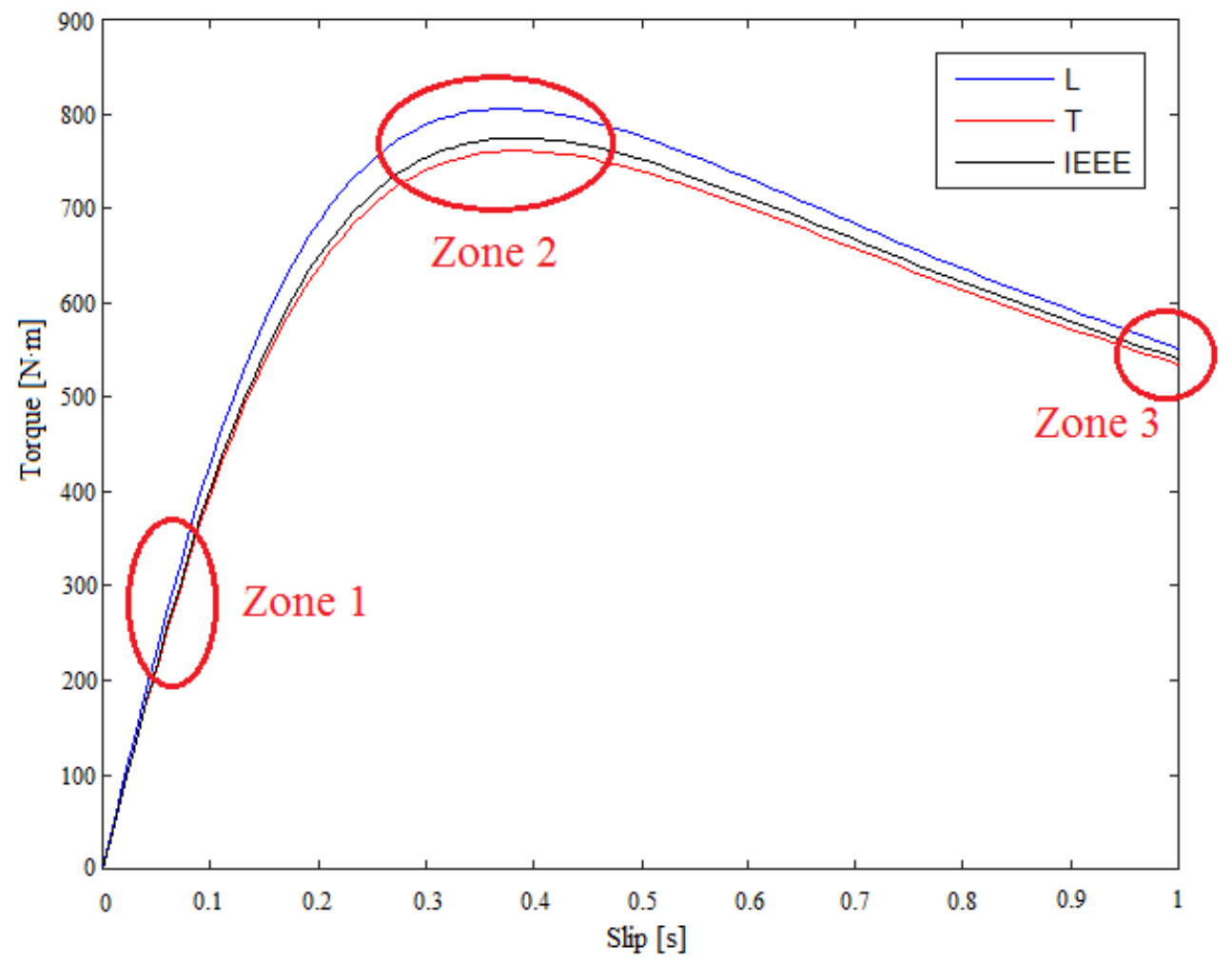

Fig. 2. Graph of slip-torque

When the starting torque values are analyzed, L type model's starting torque value is $551 \mathrm{~N} \cdot \mathrm{m}$, IEEE type model's starting torque value is $540 \mathrm{~N} \cdot \mathrm{m}$, T type model's starting torque value is $534 \mathrm{~N} \cdot \mathrm{m}$ respectively. Rated torque values are calculated for $1705 \mathrm{rpm}$ shaft speed and $\mathrm{s}_{\mathrm{n}}=0.0527 \mathrm{slip}$ value. Obtained values from the calculations, $244 \mathrm{~N} \cdot \mathrm{m}$ for L type, $228 \mathrm{~N} \cdot \mathrm{m}$ for IEEE type, $225 \mathrm{~N} \cdot \mathrm{m}$ for T type equivalent circuit respectively. Finally, when the maximum torque values are analyzed, L type model's maximum torque value is 805 $\mathrm{N} \cdot \mathrm{m}$, IEEE type model's maximum torque value is $774 \mathrm{~N} \cdot \mathrm{m}$, T type model's maximum torque value is $760 \mathrm{~N} \cdot \mathrm{m}$ respectively.

When the obtained results and experimental results are investigated from the three model, table 3 shows the errors between real and calculated values of three models respectively.

Table 3. \% Error values of torques for three equivalent circuit models

\begin{tabular}{|c|c|c|c|}
\hline Models & Starting torque error & Maximum torque error & Nominal torque error \\
\hline L Type & 4.13 & 4.01 & 4.30 \\
\hline T Type & 0.92 & -1.71 & -3.82 \\
\hline IEEE Type & 2.08 & 0.08 & -2.71 \\
\hline
\end{tabular}

When the obtained error values from three models are examined, L type equivalent circuit has highest error value for all moment types. At starting conditions, the T type equivalent circuit gives the closest value with the experimental result. At maximum torque conditions, IEEE type equivalent circuit gives the almost same value with experimental result. At rated operation conditions, IEEE equivalent circuit also gives the closest value with the experimental result. 


\subsection{Effect of rotor resistance}

One of the important parameters that influence the induction machine's performance is rotor winding resistance. Rotor winding resistance can be changed with different techniques. These techniques are, adding external resistor, changing the widths of the rotor slot openings, using double cage rotors, using long caged rotors, using different rotor slot numbers, using different materials for rotor cage structures etc. Besides, with the increasing of rotor winding resistance, starting the motor on maximum torque conditions can be provided. This situation can be seen in Fig. 3 below. Effect of the rotor resistance on starting torque, maximum torque and rated torque has been given in Fig. 3.

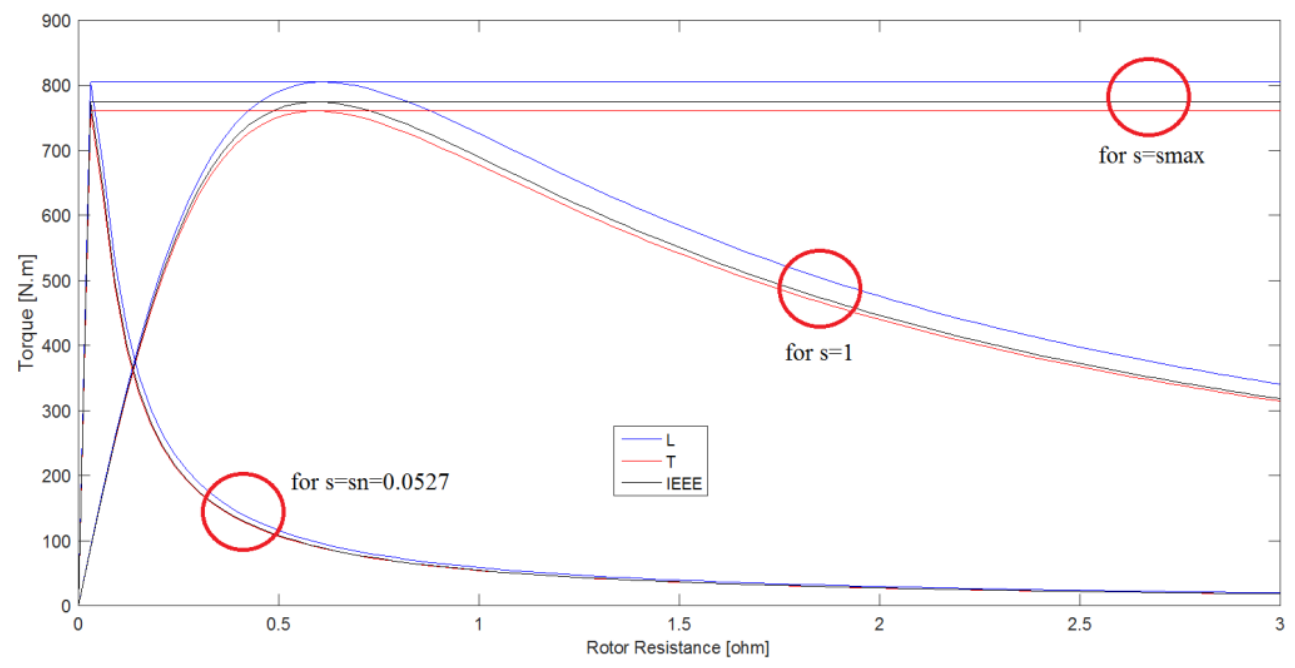

Fig. 3. Graph of rotor resistance-torque

In Fig. 3, increasing the rotor resistance does not affect the starting torque linearly. Rotor resistance increases at a certain value and starting torque increases too. After that value increasing of the rotor resistance does not affect the torque value. For the parameters such that starting torque and rated torque in the desired boundaries, an optimization process should be implemented.

\subsection{Effect of stator resistance}

In induction machines, stator winding resistance varies depended with winding conductor length, winding conductor cross-section, winding conductor number and winding conductor self-resistance. In general, stator winding resistance too smaller than rotor winding resistance. According to this feature, when calculating of the rated torque of the motor, stator winding resistance is neglected. Effect of the stator winding resistance on three torque items is given in Fig. 4.

According to Fig. 4, when stator winding resistance increases, total impedance of the equivalent circuit increases too. This effects the current and rated torque values negatively. Maximum torque and starting torque curves are quite similar but effect of the stator winding resistance on maximum torque variation is a bit bigger. 


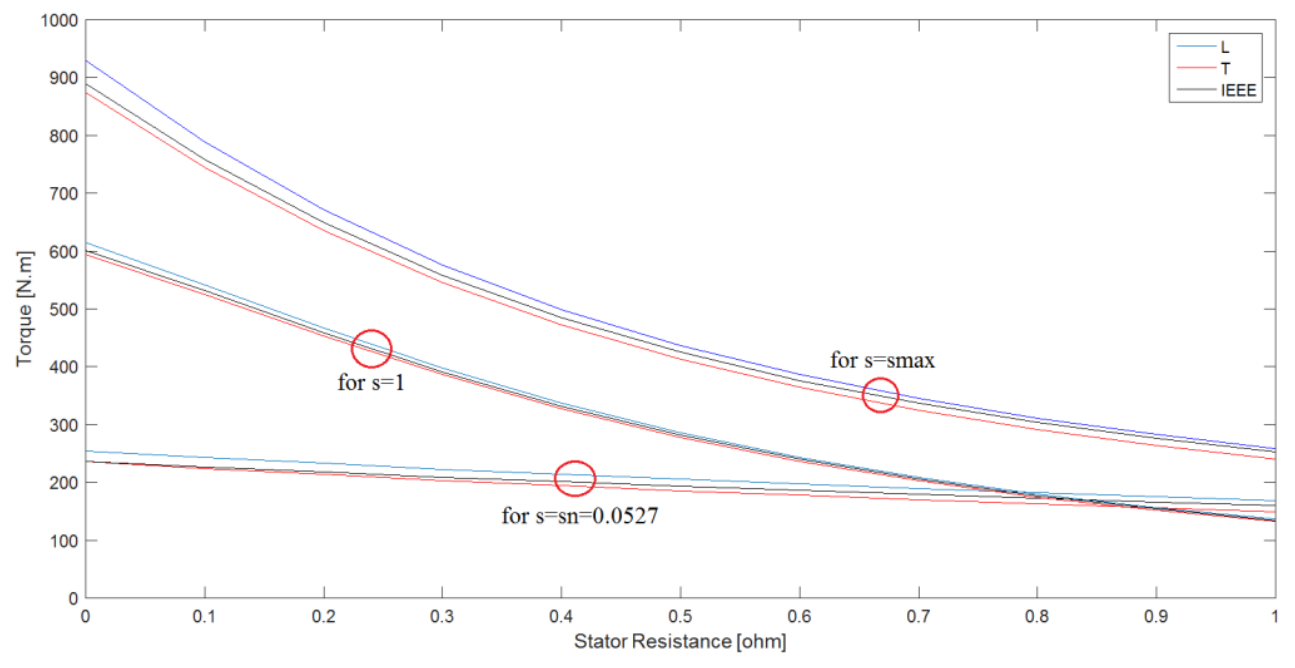

Fig. 4. Graph of stator resistance-torque

\subsection{Effect of stator and rotor reactance}

According to Biot-Savart law, in induction machines, magnetic field directly proportional with magnetic field $\left(\Phi_{m}\right)$ and current $(I) . \Phi_{m}$ is produced by magnetizing current $\left(I_{\mu}\right)$ but, stator leakage reactance $\left(X_{1}\right)$ blocks the magnetizing current. Therefore, increasing of the $X_{I}$ affects the magnetizing current and magnetizing flux, that multiplier of torque negatively.

Increasing of the rotor leakage reactance $\left(X_{2}\right)$ affects the maximum torque value negatively. Conversely, increasing of the $X_{2}$ affects the slip negatively too. Therefore, increasing of the $X_{2}$ affects the motor's performance badly.

To provide a better motor performance, $X_{1}$ and $X_{2}$ must be chosen as smaller as possible but magnetization reactance $\left(X_{m}\right)$ must be chosen as bigger as possible. Because of $X_{1}+X_{2}$ value important parameter for maximum torque, designers define the machine dimensions for a certain value of $X_{1}+X_{2}$ and they try to arrange the $X_{m}$ value as bigger as they can [21]. Effects of the stator and rotor leakage reactances on motor's starting torque and maximum torque values is shown in Fig. 5 and Fig. 6 respectively.

As seen in Fig. 5, increasing of the stator leakage reactance has an important effect on starting torque and maximum torque values. As the increasing of the stator leakage reactance, starting torque value decreases from $2500 \mathrm{~N} \cdot \mathrm{m}$ to $150 \mathrm{~N} \cdot \mathrm{m}$. Maximum torque curve changes quite similar with starting torque curve. Not like the starting torque or maximum torque, increasing of the stator leakage reactance has not an important effect on motor's rated torque. It decreases a little with the increasing of the stator leakage reactance.

When Fig. 6 is investigated, increasing of the rotor leakage reactance value causes the similar effects on both maximum torque and starting torque values. As the increasing of the rotor leakage reactance, starting torque value decreases. Maximum torque curve changes quite similar with starting torque curve. Not like the starting torque or maximum torque, increasing of the rotor leakage reactance has not an important effect on motor's rated torque. It decreases a little with the increasing of the stator leakage reactance. 


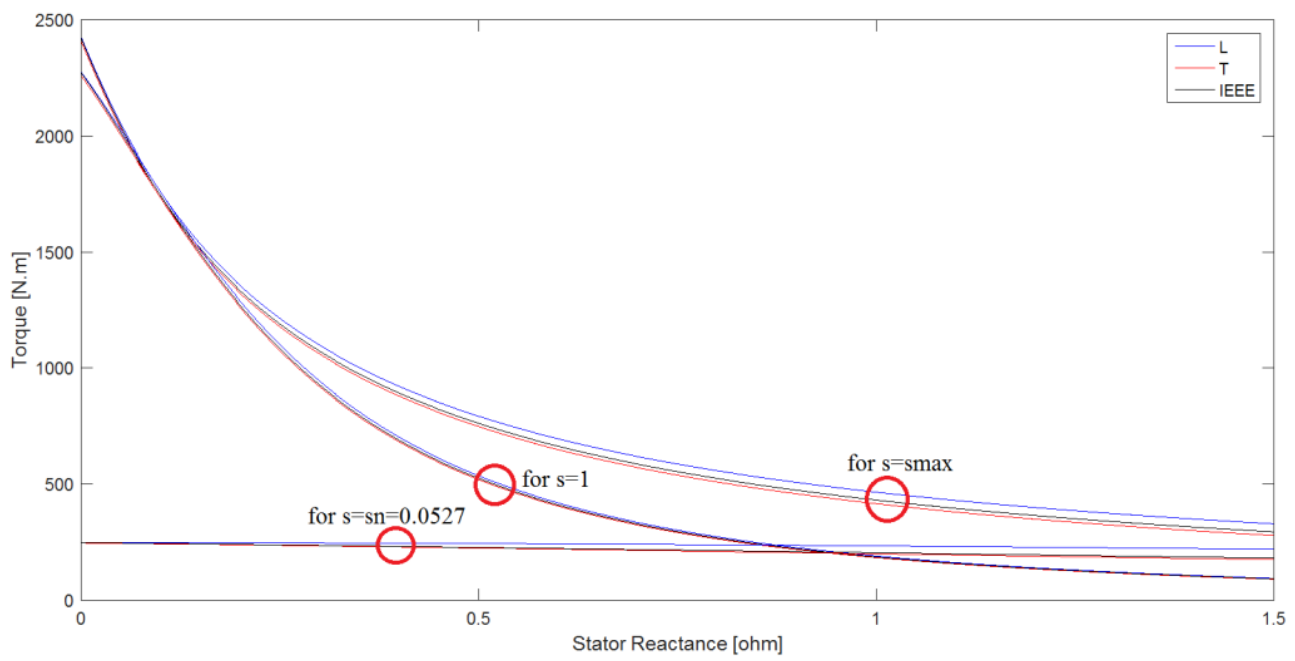

Fig. 5. Graph of stator reactance-torque

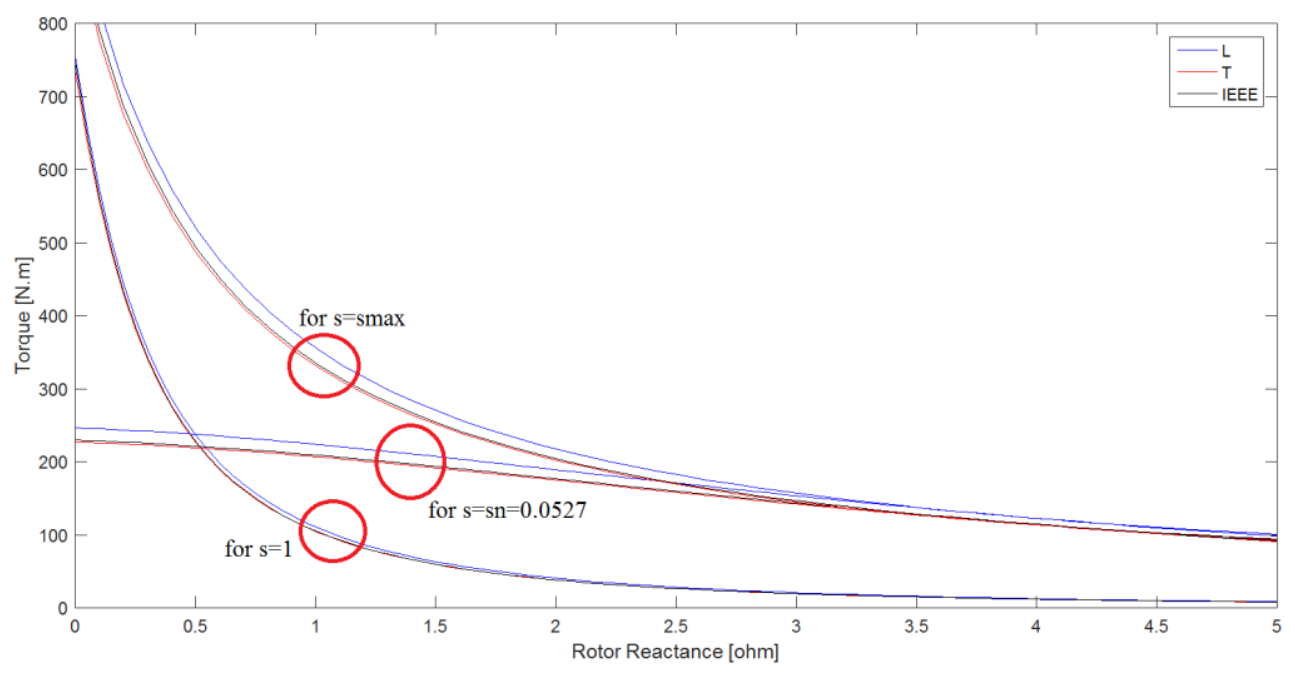

Fig. 6. Graph of rotor reactance-torque

\subsection{Effect of core resistance and magnetization reactance}

Iron resistance and magnetizing reactance are the parameters that obtained from induction motor no load test. These parameters have not any effect on starting torque, rated torque or maximum torque for L type equivalent circuit. On T type and IEEE type equivalent circuits, the magnetizing reactance has an important effect on these parameters. Iron resistance has an effect only $\mathrm{T}$ type equivalent circuit calculations. Fig. 7 and Fig. 8 shows the effects of the magnetizing reactance and iron resistance on three torque type respectively. 


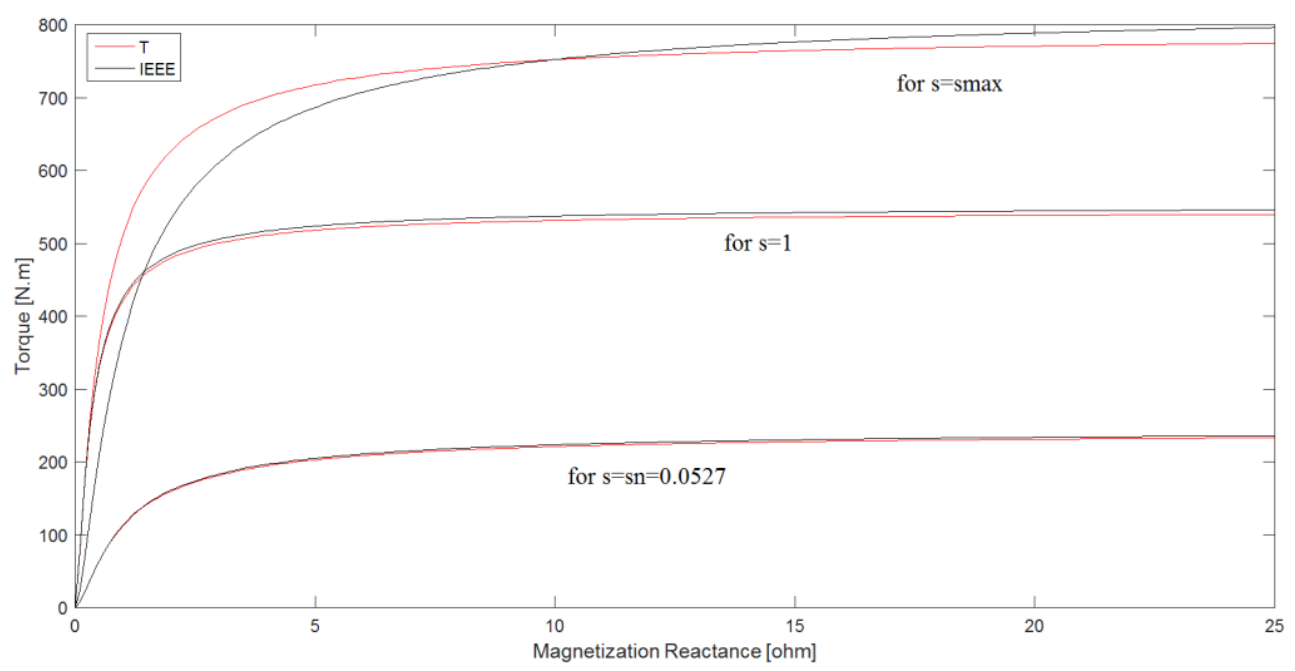

Fig. 7. Graph of magnetization reactance-torque

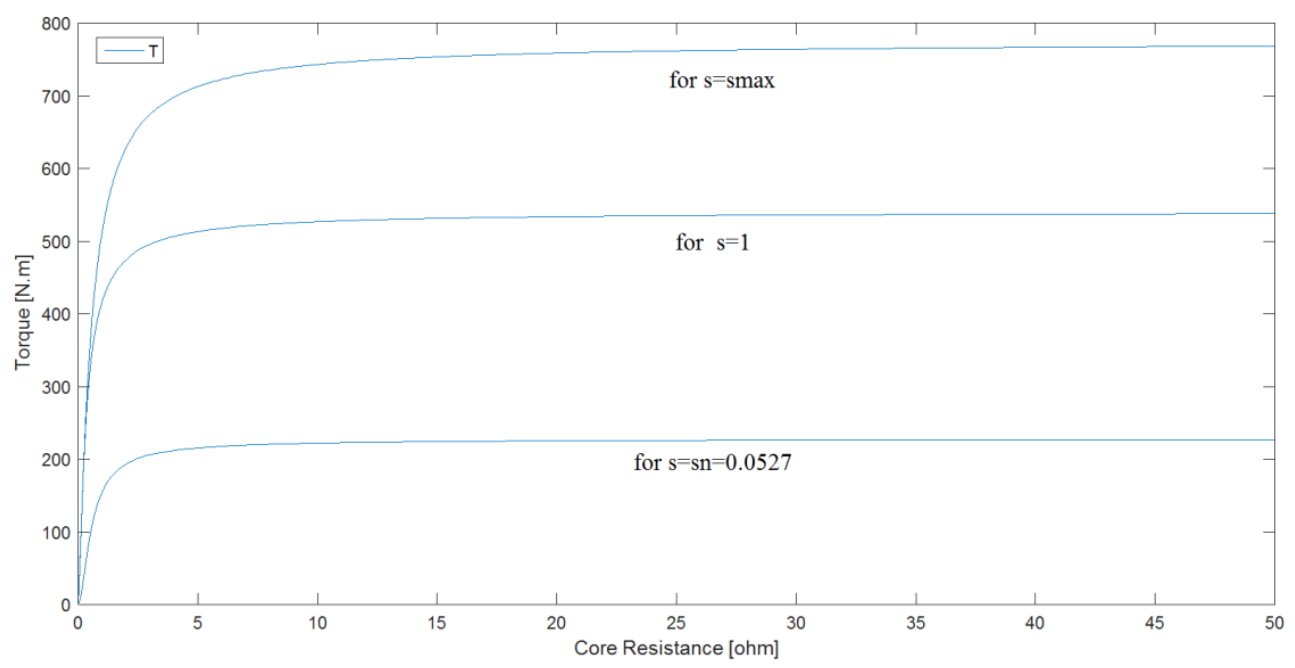

Fig. 8. Graph of core resistance-torque

As seen on Fig. 7 and Fig. 8, parameter-torque curves look like quite similar with the motor's B-H characteristic. Little changes on these two parameters have a significant influence on torque characteristics.

\section{Conclusion}

To be used in electric machinery courses, three different equivalent circuits of three-phase squirrel cage induction motor have been examined to observe the changes at starting torque, nominal torque and maximum torque. In the study, the effects of parameters such as resistance and leakage reactance of stator and rotor that affect the torque values have been investigated. The slip-torque diagram of the induction motor have been examined in three study zones and it has been determined which equivalent circuit model approximated best to the experimental results. The study is shown that important parameters for starting torque are rotor resistance and stator and rotor leakage reactances; for nominal torque, that is rotor 
resistance; and for maximum torque, those are stator and rotor reactances. The study is also shown that T-type equivalent circuit give the best approximation to experimental results in the starting torque region (Zone 3) while IEEE equivalent circuit is better in maximum torque region (Zone 2) and nominal torque region (Zone 1). However the results obtained from the $\mathrm{L}$ type equivalent circuit model are found to be far from the experimental results.

In this study, it is aimed to show the effect of the change of the equivalent circuit parameters on the torque effect of the induction motor in three important study zones according to three different equivalent circuit models which are widely used in the description of induction motors.

\section{References}

1. Y. Guan, Z.Q. Zhu, I.A.A. Afinowi, J.C. Mipo, P. Farah, Difference in maximum torque-speed characteristics of induction machine between motor and generator operation modes for electric vehicle application. Electr. Power Syst. Res. 136, 406-414 (2016)

2. Three phase induction motor. Chapter 8, 1-63.

3. M. Aydın, Y. Demir, M. Aydın, Flux skew SEA ile üç fazlı bir asenkron motorun moment-kayma analizi. MDS Bulletin 11, 1-2 (2014)

4. M. Aydın, Y. Demir, M. Aydın, SPEED yazılımı ile üç fazlı asenkron motor analizi. MDS Bulletin 15, 1-2 (2015)

5. B. Saraçoğlu, U. Güvenç, M. Dursun, G. Poyraz, S. Duman, Estimation of the induction motor parameters using biogeography based optimization method. J. Adv. Technol. Sci. 2, 46-54 (2013)

6. D. Pejovski, B. Velkovski, Calculation of induction motor starting parameters using MATLAB. Infoteh Jahoriina 15, 879-884 (2016)

7. Torque characteristics of nema design a,b,c,d \& e motors. 1-2

8. S. Şal, M. Imeryüz, L.T. Ergene, The analysis of the squirrel cage induction motor rotor bars under the cost constraint. Chamber Electr. Eng. Sci. J. 2, 23-28 (2012)

9. S. Kül, Effect of rotor parameters to traction induction motor performance, Power Systems Conference, 1-4 (2016)

10. A. Uşüdüm, Standart bir sincap kafesli asenkron motorun, ansys rmxprt ve maxwell yazılımları ile analizi asenkron motor analizi. Arge Dergisi, 28-32 (2013)

11. M. Fidan, M. Sersöz, Motor torque effect on energy efficiency of CER motors. $3^{\text {rd }}$ International Symposium on Railway Systems Engineering 1, 245-249 (2016)

12. P. Aree, Analytical approach to determine speed-torque curve of induction motor from manufacturer data. Procedia Comput. Sci. 86, 293-296 (2016)

13. V.P. Sakthivel, S. Subramanian, Bio-inspired optimization algorithms for parameter determination of three-phase induction motor. COMPEL: Int. J. Comput. Math. Electr. Electron. Eng. 31, 528-551 (2012)

14. H.K. Jafari, L.M.F. Corcoles, J. Pedra, Using the instantaneous power of a free acceleration test for squirrel-cage motor parameters estimation. IEEE Trans. Energy Convers. 30, 974-982 (2015)

15. T. Phumiphak, C. Chat-uthai, Estimation of induction motor parameters based on field test coupled with genetic algorithm. International Conference on Power System Technology. Proceedings PowerCon 2002, 1199-1203 (2002) 
16. M.A.A. Morad, E.F. El-Saadany, Estimation of induction motor single-cage model parameters from manufacturer data. Power and Energy Society General Meeting (PES), 2013 IEEE, Vancouver, BC, Canada, 1-5 (2013)

17. A.F. Mergen, S. Zorlu, Elektrik Makinaları 2, Asenkron Makinalar. Birsen Yayınevi, İstanbul, 1-256, (2005)

18. S. Sehra, K.K.Gautam, V. Bhuria, Performance evaluation of three phase induction motor based on no load and blocked rotor test using matlab. Int. J. Sci. Environ. Technol. 1, 541-547 (2012)

19. Asenkron motorlarda moment. 1-28

20. P. Pillay, R. Nolan, T. Haque, Application of genetic algorithms to motor parameter determination for transient torque calculations. IEEE Trans. Ind. Appl. 33, (1997)

21. M. Turan, The analysis of the harmonic reactances and torques on the expanded equivalent circuit of the induction machine. Master Thesis, Sakarya University, Institute of Science and Technology, Sakarya, 1-97 (1996) 